\title{
GAMBARAN PEMAKAIAN DIAPERS SEKALI PAKAI PADA ANAK USIA PRASEKOLAH
}

\author{
Ns. Lita \\ PSIK STIKes Hang Tuah Pekanbaru \\ Email: lita_0824@yahoo.com
}

\begin{abstract}
This study is to identify the picture of the use of disposable diapers in children aged prasekolah. Desain used in this study is a simple descriptive with cross sectional approach. A sample of 57 people at Tk Az-Zuhra village Pekanbaru Simpang Tiga. The analysis used is a univariate analysis with frequency distribution. The results of this study found that the average age is 30.56 years old mother, the mother's last majority of education is higher education (50.9\%), most of the work mothers are housewives (43.9\%), the economic status of many with moderate status (54.4\%). Most were female gender (57.9\%), the average age was 48.14 months and age started using diapers 7.84 a month, and impaired skin as much as $36.8 \%$. From the research results are expected to improve the mother's knowledge about the impact of using diapers to preschoolers who are at Tk Az-Zuhra village Pekanbaru Simpang Tiga.
\end{abstract}

Key word : diapers, kids.

\section{PENDAHULUAN}

Anak usia Prasekolah adalah usia 3-5 tahun dimana pada masa ini, petunjuk bimbingan tetap diperlukan walaupun kesulitannya lebih sedikit dibandingkan tahun sebelumnya, usia prasekolah atau masa kanak-kanak memiliki perkembangan biologis, psikososial, perkembangan kognitif, moral, spiritual, citra tubuh, dan sosial yang akan mempengaruhi tumbuh kembang anak yang seharusnya umur prasekolah sudah bisa melepaskan diapers (Susilaningrum, 2013).

Popok atau diapers sekali pakai menjadi pilihan yang paling populer bagi orang tua karena popok mudah di gunakan, tidak harus mencucinya, tanpa memikirkan efek samping yang akan terjadi termasuk bakteri dan jamur, disamping itu juga terdapat bahan kimia yang menyebabkan kemerahan karena kondisi yang lembab dan tersedianya faktor pendukung kehidupan jamur yang menyebabkan timbulnya gangguan kesehatan anak, di sebabkan diapers yang tidak steril atau kekeliruan dalam penggunaannya (William, 2014).

Sharhanis, A., Turn, CJ., McLaughry, E., Hartin, K., Hayes, M. (2011) mengemukakan bahwa bayi di Amerika menghabiskan sekitar 2,5 tahun menggunakan diapers dan rata-rata menggunakan 4 buah diapers per hari, 1500 diapers per tahun, dan 3796 diapers sepanjang hidupnya. Di Indonesia yang memiliki penduduk 220-240 juta jiwa, maka setidaknya ada 22 juta balita di Indonesia, dan 1/3 dari jumlah bayi di Indonesia mengalami ruam popok. Penggunaan diapers dapat menyebabkan berbagai macam permasalahan, diantaranya seperti yang dikatakan oleh Susilaningrum (2013) adalah ruam popok, kerusakan kulit atau iritasi. Pemakaian diapers menyebabkan gumpalan di antara tungkai yang berpotensi memperlebar jarak diantara tungkai tersebut. Hal ini dapat disimpulkan bahwa pemakaian diapers pada anak mempengaruhi gaya berjalan anak, yaitu mengangkang. Wong (2008) juga mengatakan bahwa dampak lain penggunaan diapers adalah dermatitis yang disebabkan oleh kontak yang lama dan berulang dengan iritan seperti urine, feses dan gesekan.

\section{METODOLOGI PENELITIAN}

Penelitian ini menggunakan jenis penelitian deskriptif sederhana dengan desain CrossSectional.Penelitian ini bertujuan untuk mengetahui gambaran pemakaian diapers sekali pakai pada usia prasekolah di Simpang Tiga Pekanbaru. Pengambilan sampel dalam penelitian ini menggunakan rumus sebagai berikut: 
$n=\frac{N}{1+N(\mathrm{~d})^{2}}$

Keterangan:

$n=$ Besar Populasi

$\mathrm{N}=$ Besar Sampel

$\mathrm{D}=$ Tingkat kesalahan yang dapat ditolerir $(0,1)$

$$
\begin{aligned}
& n=\frac{N}{1+N(\mathrm{~d})^{2}} \\
& n=\frac{133}{1+133(0.1)^{2}} \\
& n=\frac{133}{1+133(0,01)} \\
& n=\frac{133}{1+1,33} \\
& n=\frac{133}{2,33} \\
& n=57,08(57 \text { orang) }
\end{aligned}
$$

Jumlah sampel untuk tiap-tiap kelas TK di peroleh dengan menggunakan rumussebagai berikut:

$N i=\frac{N i \times n}{N}$

Keterangan:

ni $\quad=$ Besaran sampel tiap kelas

$\mathrm{N}=$ Populasi keseluruhan

$\mathrm{Ni}=$ Populasi tiap kelas

Jumlah sampel masing-masing kelas yang diteliti di Tk Az-zuhra simpang tiga Pekanbaru.

\begin{tabular}{|c|c|c|c|}
\hline No & Kelas & Rumus & Jumlah \\
\hline 1 & $\mathrm{~A}$ & $\begin{array}{l}n i=\frac{25 \times 57}{133} \\
=10,7\end{array}$ & 11 \\
\hline 2 & $\mathrm{~B}$ & $\frac{27 \times 57}{133}=11,57$ & 11 \\
\hline 3 & $\mathrm{C}$ & $\frac{27 \times 57}{133}=11,57$ & 12 \\
4 & $\mathrm{D}$ & $\begin{array}{l}n i=\frac{27 \times 57}{133} \\
=11,57\end{array}$ & 12 \\
\hline 5 & $\mathrm{E}$ & $n i=\frac{27 \times 57}{133}$ & 12 \\
\hline \multicolumn{3}{|c|}{ Total } \\
\hline
\end{tabular}

\section{HASIL DAN PEMBAHASAN}

\section{Tabel 1.}

Karakteristik responden berdasarkan Usia ibu,

Usia Anak dan Usia Mulai Menggunakan

Diapers di TK Az-zuhra Simpang Tiga

Pekanbaru.

\begin{tabular}{ccccccccc}
\hline $\begin{array}{c}\text { Katego } \\
\text { ri }\end{array}$ & $\mathbf{N}$ & $\%$ & $\begin{array}{c}\text { Me } \\
\text { an }\end{array}$ & $\begin{array}{c}\text { Med } \\
\text { ian }\end{array}$ & $\begin{array}{c}\text { Mo } \\
\text { dus }\end{array}$ & SD & $\begin{array}{c}\text { M } \\
\text { in }\end{array}$ & $\begin{array}{c}\text { M } \\
\mathbf{a x}\end{array}$ \\
\hline Usia & 5 & 1 & 30, & 29 & 27 & 4,8 & 24 & 41 \\
Ibu & 7 & 0 & 56 & & & 99 & & \\
& & 0 & & & & & & \\
\hline
\end{tabular}

\begin{tabular}{ccccccccc}
\hline $\begin{array}{c}\text { Katego } \\
\text { ri }\end{array}$ & $\mathbf{N}$ & $\%$ & $\begin{array}{c}\text { Me } \\
\text { an }\end{array}$ & $\begin{array}{c}\text { Med } \\
\text { ian }\end{array}$ & $\begin{array}{c}\text { Mo } \\
\text { dus }\end{array}$ & SD & $\begin{array}{c}\text { M } \\
\text { in }\end{array}$ & $\begin{array}{c}\text { M } \\
\text { ax }\end{array}$ \\
\hline Usia & 5 & 1 & 48, & 48 & 48 & 0,7 & 36 & 60 \\
Anak & 7 & 0 & 14 & & & 89 & & \\
& & 0 & & & & & & \\
\hline Usia & 5 & 1 & 7,8 & 8 & 8 & 2,3 & 3 & 13 \\
mulai & 7 & 0 & 4 & & & 36 & & \\
menggu & & 0 & & & & & & \\
nakan & & & & & & & & \\
diapers & & & & & & & &
\end{tabular}

Hasil penelitian ini didapatkan didapatkan bahwa rata-rata (mean) usia ibu adalah 30,56 tahun, dengan usia termuda 24 tahun dan usia tertua 41 tahun, rata-rata usia anak saat penelitian adalah 48,14 tahun dengan usia usia termuda 36 bulan dan tertua adalah 60 bulan. Selanjutnnya. rata-rata usia anak mulai menggunakan diapers adalah 7,84 bulan dengan usia terendah 3 bulan dan tertinggi 13 bulan.

Tabel 2.

Karakteristik responden berdasarkan Usia ibu, Usia Anak dan Usia Mulai Menggunakan Diapers di TK Az-zuhra Simpang Tiga Pekanbaru.

\begin{tabular}{c|cc}
\hline Karakteristik Ibu & F & $\%$ \\
\hline
\end{tabular}
Pendidikan terakhir:

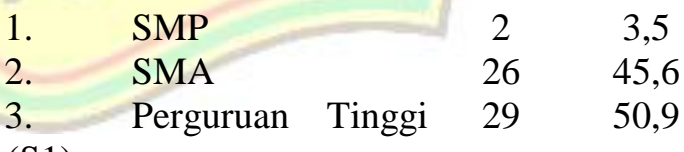

(S1)

Pekerjaan:

\begin{tabular}{llll} 
1. IRT & 25 & 43,9 \\
2. Wiraswasta & 11 & 19,3 \\
3. & PNS & 21 & 36,8 \\
Status ekonomi & & \\
1. & Tinggi & 26 & 45,6 \\
2. Menengah & 31 & 54,4 \\
\hline \multicolumn{4}{l}{ Jenis kelamin anak } \\
1. $\quad$ Laki-laki & 24 & 42,1 \\
\hline
\end{tabular}




\begin{tabular}{lccc}
2. & Perempuan & 33 & 57,9 \\
\hline Total: & & $\mathbf{5 7}$ & $\mathbf{1 0 0}$ \\
\hline
\end{tabular}

Hasil penelitian ini didapatkan bahwa karakteristik ibu yang memiliki anak menggunakan diapers yaitu pendidikan terakhir yang terbanyak adalah perguruan tinggi 29 orang $(50,9 \%)$, pekerjaan terbanyak adalah ibu rumah tangga 25 orang $(43,9 \%)$ dan 31 orang $(54,4 \%)$ dengan status ekonomi menengah. Sedangkan untuk jenis kelamin anak mayoritas adalah perempuan 33 orang $(57,9 \%)$.

\section{Tabel 3.}

Distribusi Frekuensi Anak yang Mengalami Gangguan Kulit di TK Az-zuhra Simpang Tiga Pekanbaru.

\begin{tabular}{ccc}
\hline Gangguan kulit & F & $\mathbf{\%}$ \\
\hline $\begin{array}{c}\text { Ada gangguan kulit } \\
\text { Tidak ada gangguan } \\
\text { kulit }\end{array}$ & 21 & 36,8 \\
\hline Total: & 36 & 63,2 \\
\hline
\end{tabular}

Table 3 menunjukkan terdapat anak yang mengalami gangguan kulit yaitu 21 orang $(36,8 \%)$.

\section{Usia Ibu dan anak}

Hasil penelitian didapatkan rata-rata usia ibu 30,56 tahun dengan usia tertua 41 tahun dan usia termuda 24 tahun. Usia mempengaruhi terhadap daya tangkap dan pola pikir. Semakin bertambah usia semakin berkembang pula daya tangkap dan daya pikir. Usia dewasa tengah individu akan lebih berperan aktif dalam kehidupan sosial serta lebih banyak melakukan persiapan demi suksesnya upaya menyesuaikan diri menuju usia tua, selain itu usia dewasa tengah akan lebih banyak menggunakan waktu untuk membaca kemampuan intelektual pemecahan masalah (Notoatmodjo, 2003). Faktor usia mempengaruhi jumlah pengalaman yang dimiliki individu. Pengalaman merupakan suatu yang pernah di alami ibu yang akan menambah pengetahuan atau wawasan yang bersifat nonformal, salah satunya adalah pengalaman mengasuh anak. Usia ibu juga dapat mempengaruhi dalam hal penggunaan diapers pada anak. Pada usia ini memang sering dihubungkan dengan masa subur atau usia produktif dalam menapak karir yang penuh kesibukan di luar rumah sehingga ibu lebih dominan untuk memilih penggunaan diapers pada anak. Ibu yang memiliki usia lebih muda mempunyai kebiasaan yang dominan terhadap ketergantungan penggunaan diapers pada anak bila dibandingkan dengan usia ibu yang lebih tua.

Usia anak pada penelitian ini rata-rata 48,14 bulan dengan usia tertua 60 bulan dan usia termuda 36 bulan masih menggunakan diapers. Hasil penelitian ini menunjukkan bahwa fase perkembangan anak usia toddler (1-3 tahun) belum tercapai dimana pada usia ini harusnya anak sudah siap untuk dilakukan toilet training. Kemampuan sfingter uretra untuk mengontrol rasa ingin berkemih dan sfingter ani untuk mengontrol rasa ingin defekasi mulai berkembang pada usia toddler. Penggunaan diaper secara rutin sampai anak berusia 3-5 tahun dapat berakibat terlambatnya kemampuan anak dalam mengontrol buang air kecil dan buang air besar. Pada usia 3-5 tahun ini, anak sudah mulai melakukan pemberontakan terhadap orang tua jika ada hal yang tidak sesuai dengan keinginan atau kemauannya.

Penggunaan diapers yang terlalu lama pada anak dapat mengakibatkan dampak negatif terhadap kesiapan toilet training pada anak. Karena dengan kebiasaan menggunakan diapers maka seorang anak akan mendapatkan kenyamanan dari kebiasaan itu, sehingga membuat anak menjadi sulit juga untuk meninggalkan ketergantungan terhadap penggunaan diapers. Sehingga lama kelamaan kebiasaan dari penggunaan diapers itu jika dibiarkan maka akan menghambat dari pelaksaan toilet training. Berbeda/dengan anak yang terbiasa tidak menggunakan diapers maka anak tidak akan mendapatkan kenyamanan ketika sudah BAK/BAB karena merasa risih sehingga melatih stimulus dan sensitifitas anak dalam hal mengutarakan atau menyampaikan pada orang tua jika $\mathrm{BAK} / \mathrm{BAB}$ dan dapat menunjang dari kesiapan anak untuk toilet training. Sehingga dapat disimpulkan bahwa penggunaan diapers yang terlalu sering dan lama dapat menyebabkan kesiapan toilet training pada anak kurang. Hal ini sesuai dengan teori yang diungkapkan oleh Warner \& Kelly (2006) bahwa salah satu yang 
dapat mempengaruhi kesiapan toilet training adalah kebiasaan (penggunaan diapers).

\section{Pendidikan Ibu}

Hasil penelitian menunjukkan bahwa paling banyak tingkat pendidikan ibu yang memiliki anak usia prasekolah yang menggunakan diapers sekali pakai adalah perguruan tinggi yaitu sebanyak 29 orang atau 50,9\%. Pendidikan adalah suatu usaha untuk mendapatkan kepribadian dan kemampuan didalam dan diluar sekolah dan berlangsung seumur hidup (Notoatmodjo, 2009). Pendidikan akan memberikan dampak bagi pola pikir dan pandangan hidup dalam penggunaan diapers pada anak karena semakin tinggi pendidikan ibu, maka akan memiliki wawasan yang luas dan lebih mudah untuk menerima perubahan dari pada ibu yang yang berpendidikan rendah. Ibu yang memiliki pendidikan tinggi lebih memilih gaya hidup modern dan akan lebih condong untuk meninggalkan kebiasaan lama seperti penggunaan popok kain dan lebih memilih untuk menggunakan diapers pada anak.

\section{Status Ekonomi dan Pekerjaan Ibu}

Hasil penelitian didapatkan bahwa status ekonomi ibu sebagian besar tergolong menengah yaitu sebanyak 31 orang atau $54,4 \%$ sebagian besar ibu bekerja sebagai ibu rumah tangga, yaitu sebanyak 25 orang atau $43,9 \%$. Pekerjaan juga dapat mempengaruhi ibu untuk menggunakan diapers pada anak. Ibu yang memiliki pekerjaan swasta lebih mempunyai sedikit waktu dalam mengasuh anak dibandingkan dengan ibu rumah tangga atau ibu yang bekerja PNS dan wiraswasta sehingga lebih memilih praktis untuk menggunakan diapers pada anak dengan alasan agar pengasuh tidak terlalu repot karena sebagian besar ibu yang bekerja swasta memilih memberikan tanggung jawab untuk merawat anak pada nenek. Pekerjaan juga mempengaruhi status ekonomi ibu dan keluarga dan mendukung tersedianya modal dalam penyediaan fasilitas yang dibutuhkan keluarga khususnya dalam pemakaian diapers. Orang tua yang memiliki tingkat ekonomi rendah, maka memiliki kecenderungan untuk menghemat pengeluaran keluarga, salah satunya tidak menggunakan diapers pada perawatan anak. Hubungan status ekonomi keluarga dengan penggunaan diapers sebagaimana ditunjukkan dalam penelitian Nining (2013) yang menyatakan bahwa salah satu faktor yang berhubungan dengan intensitas penggunaan diapers pada anak toddler adalah tingkat sosial ekonomi keluarga, dimana semakin tinggi tingkat sosial ekonomi keluarga, maka intensitas penggunaan diapers semakin meningkat.

\section{Jenis kelamin anak}

Jenis kelamin anak merupakan salah satu faktor yang juga dapat mempengaruhi kesiapan toilet training pada anak. Anak perempuan sesungguhnya lebih displin dalam penerapan toilet training hanya saja pada hasil penelitian ini diperoleh jenis kelamin perempuan lebih dominasi dari laki-laki sehingga jumlah perbandingan antara laki-laki dan perempuan tidak seimbang. Hasil penelitian ini juga didapatkan bahwa sebagian besar responden memiliki kesiapan toilet training yang kurang, oleh karena itu hasil penelitian ini bertolak belakang dengan teori yang diungkapkan oleh Gilbert (2008), bahwa anak laki-laki cenderung lebih lambat dalam penguasaan kontrol terhadap kandung kemihnya dibandingkan anak perempuan. Hal ini disebabkan sistem syaraf anak laki-laki berkembang lebih lama daripada anak perempuan, anak perempuan dapat mulai menguasai keinginan buang airnya pada umur 18 bulan, sementara anak laki-laki baru menguasai saat berumur 22 bulan.

\section{Dampak Pemakaian Diapers: Ruam Popok}

Hasil penelitian didapatkan sebanyak 21 orang dari 57 anak (36,8\%) mengalami gangguan kulit akibat pemakaian diapers. Hal ini sejalan dengan hasil penelitian Sujatni (2013) bahwa sebagian besar anak mengalami ruam popok yaitu sebanyak 9 orang $(8,0 \%)$ yang disebabkan oleh iritasi terhadap kulit yang tertutup oleh diapers setelah anak BAB dan BAK. Hal ini juga dibahas oleh Susilaningrum et.al (2013) bahwa kontak yang lama antara kulit dan diapers yang basah 
mempengaruhi beberapa bagian kulit, sehingga kulit menjadi sensitif dan mudah mengalami iritasi. Penelitian lain terkait ruam popok dilakukan oleh Ramba dan Nurbaya (2014) tentang kejadian iritasi kulit (ruam popok) pada bayi usia 0-12 bulan di RSUP Wahidin Sudirohusodo Makassar bahwa dari 23 orang anak yang diteliti hanya 1 orang yang tidak mengalami ruam popok ada hubungan popok kotor, alergi kulit, dan lapisan plastik kedap air (sirkulasi) dengan tingkat kejadian iritasi kulit (ruam popok) pada bayi. Hal ini dikarenakan popok kotor, adanya alergi pada kulit (ruam popok) pada bayi. Sehingga diharapkan kepada semua diharapkan agar lebih memperhatikan lagi tentang iritasi kulit (ruam popok) pada bayi.

Selain itu, Sherly (2010) juga mengemukakan popok yang basah bila tidak segera di ganti akan membuat kulit bayi lembab. Di dalam urine terdapat berbagai organisme diantaranya baktrium amoniageenes yang dapat mengubah urea menjadi amonia. Amonia ini dapat meningkatkan $\mathrm{pH}$ pada perumkaan kulit bayi sehingga kulit akan lebih mudah dan sering diserang oleh kuman dan jamur. Gesekan dan iritasi merupakan dua faktor yang penting sebagai penyebab primer maupun sebagai faktor pencetus.

\section{KESIMPULAN DAN SARAN}

1. Karakteristik Ibu meliputi usia termuda 24 tahun dengan jumlah 22 orang presentase $(46,8 \%)$, usia tertua 41 tahun sebanyak 16 orang presentase $(34,0 \%)$. Sebagian besar Ibu berpendidikan perguruan tinggi S1, yaitu 24 orang $(51,1 \%)$. Sebagian besar ibu bekerja sebagai IRT, yaitu sebanyak 25 orang $(43,9)$. Sebagian besar status ekonomi Ibu tergolong sedang, yaitu sebanyak 31 orang $(54,4 \%)$.

2. Karakteristik anak yang tertua berusia 60 bulan dan yang termuda berusia 3 bulan, sebagian besar anak berjenis kelamin perempuan, yaitu sebanyak 33 orang $(57,9 \%)$, sebagian besar anak sudah menggunakan diapers saat berumur 8 bulan, dari 57 anak yang mengalami gangguan kulit ada 21 orang $(36,8 \%)$, yang tidak memiliki gangguan 36 orang dengan $(63,2 \%)$.

\section{Saran}

1. Bagi Ibu

Melepaskan diapers pada saat anak siap melakukan toilet training yaitu pada usia toddler

\section{Bagi Pelayanan Keperawatan}

Hasil penelitian ini diharapkan dapat memberikan informasi kepada petugas kesehatan khususnya perawat anak sehingga dapat meningkatkan promosi kesehatan dalam menerapan dampak diapers pada anak 3-5 tahun.

\section{DAFTAR PUSTAKA}

Gilbert, Jane. (2003). Latihan Toilet. Jakarta, Erlangga.

Nining. F. 2013. Pengaruh PolaAsuh Orang Tua dan Intensitas Penggunaan Diapers terhadap Tingkat Kesiapan Toilet Training pada Anak Usia Toddler di Little Care Stikes Surya Global Yogyakarta. Publikasi Thesis. Surakarta: Program Pasca Kedokteran Fakultas Kedokteran Universitas Sebelas Maret.

Notoatmodjo, S. (2003). Ilmu kesehatan masyarakat. Jakarta: RinekaCipta. . (2009). Pengembangan sumber daya manusia. Jakarta: Anggota IKAPI. . (2010). Metodologi penelitian kesehatan. Jakarta: Rineka Cipta.

Ramba, H. L., \& Nurbaya, S. (2014). Kejadian iritasi kulit (ruampopok) bayi usia0-12 bulan. Journal of pediatric nursing vol. (2). Diperoleh dari http://library.stikesnh.ac.id.

Sharhanis, A., Turn, CJ., McLaughray, E., Hartin, K., Hayes, M. (2011). Susainabiliy assessment: seventeen generation diapers vesus diapers. Diperoleh dari http://www.uvm.edu/ shali/diapers.pdf.

Susilaningrum. R., Nursalam., \& Utami. S., (2013) Asuhan keperawatan bayi dan 
anak: untuk perawat dan bidan Edisi 2, Jakarta: Salemba Medika.

Sherly. A. (2010). Pengetahuan ibu tentang ruam pokok pada bayi di ruangan kamarl RSUD Arifin Ahmad pekanbaru. Skripsi tidak dipublikasikan.
Warner, P \& Kelly, P. (2006). Mengajari Anak Pergi Ke Toilet. Jakarta, Arcan

Williams. (2014). Baby care day by day. Depok: Pustaka Bunda.

Wong. D. L, (2008). Buku ajar keperawatan pediatric Vol 1. Jakarta: EGC.

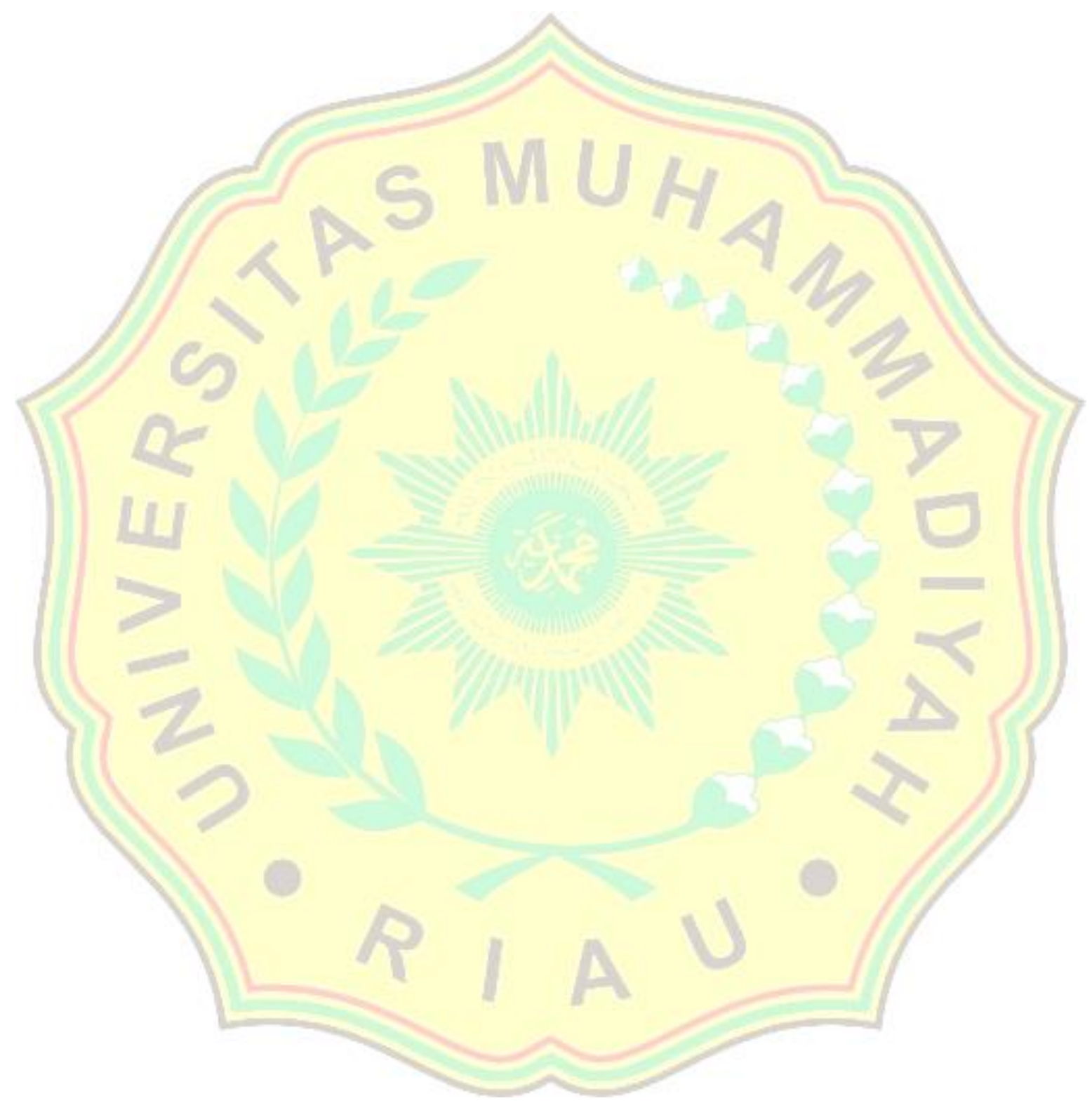

